\title{
Profesión periodística y Unión Europea: hacia una unificación de la reglamentación dentro de la profesión periodística ${ }^{1}$
}

\section{Elena Real}

Profesora de Ética y Desontología de la Información.

Universidad Complutense de Madrid

Resumen:

La invitación a la profesionalización de la actividad periodística ha de hacerse extensible a todos los países de la UE. Conviene, para evitar dificultades que enquisten la libre circulación de trabajadores entre los diferentes estados, partir de un escenario común, al menos, en sus líneas esenciales. El derecho a ejercer una ocupación o profesión en otro país miembro no debe suponer bajo ningún concepto un agravio comparativo ni para el inmigrante ni para los nacionales de ese estado. Este artículo aborda el análisis de esta problemática y el reto que plantea el acercamiento de las distintas concepciones de periodismo y periodista.

Palabras clave:

Profesión periodística, libre circulación de profesiones.

\section{Abstract:}

The invitation to professionalize the journalistic activity has to extend to all the countries of the EU. To avoid difficulties that obstruct free circulation of workers between the different states, it is advisable from a common setting, at least in its essential lines. The right to practise an occupation or profession in another

\footnotetext{
${ }^{1}$ Este artículo, revisado y actualizado, es un extracto de la tesis doctoral de su autora titulada: Formación y ejercicio profesional del periodista en la España del siglo XXI dentro del marco de la Unión Europea (2 vol.). Universidad Complutense de Madrid. Fue dirigida por el profesor Francisco Vázquez Fernández y defendida el 9 de marzo de 2004 en la Facultad de Ciencias de la Información. Obtuvo la calificación de Sobresaliente cum laude por unanimidad. En junio de 2005, la Universidad Complutense la distinguió con el premio extraordinario de doctorado.
} 
country member must not suppose, under any concept, a comparative offense eihter for the inmigrant or for the natives of that state. This article approaches the analysis of this topic and the challenge that raises from the approach of the different conceptions of journalism and journalist.

Key words:

Journalistic profession, free circulation of professions.

\section{Unión Europea y libre circulación de profesionales}

La creación de un mercado unificado en el que circulasen libremente las personas, los capitales, los bienes y los servicios, ha sido uno de los objetivos de la Comunidad Europea (hoy Unión Europea) desde su constitución. El Acta Única Europea -que vino a completar el Tratado de Roma- permitió instaurar a partir del 1 de enero de 1993 un gran mercado interior europeo, un espacio sin fronteras entre sus Estados miembros. Esto implica, para el tema que ahora nos ocupa, que los ciudadanos de la Unión Europea pueden ejercer su actividad profesional en el país miembro de su elección. Este libre ejercicio de la profesión en toda la Unión debe efectuarse sin ninguna barrera susceptible de complicar o desalentar las migraciones².

El Título III del Tratado Constitutivo de la Comunidad Europea (CE) contiene las disposiciones relativas a la libre circulación de personas, servicios y capitales. Entre otros aspectos, impide la exclusión por razones de nacionalidad, organiza la libre circulación de trabajadores asalariados y permite a los no asalariados ejercer sus actividades profesionales en otro país miembro, a título permanente (derecho de establecimiento) o mediante prestaciones transfronterizas de servicios (ejercicio temporal en otro país aunque se siga establecido en el país de origen) ${ }^{3}$.

El Derecho europeo prohíbe desde 1970 cualquier discriminación de nacionalidad entre ciudadanos de la Unión en materia de acceso al empleo, exceptuando ciertas actividades que impliquen participación en el ejercicio de la autoridad pública y la salvaguarda de los intereses generales del Estado. Los reglamentos comunitarios han procedido con bastante rapidez a la aplicación de los principios de la libre circulación y de la igualdad en la remuneración de los trabajadores asalariados. Tratándose de trabajadores independientes, el Tribunal de Justicia europeo juzgó, en 1974, en sus sentencias Reyners y Van

\footnotetext{
${ }^{2}$ Los países europeos no miembros de la UE firmantes del Acuerdo sobre el EEE se han sumado también a esta iniciativa, por lo que a efectos de la libre circulación de trabajadores son equiparables prácticamente a los Estados integrantes de la UE.

${ }^{3}$ España ha ratificado ya convenientemente el contenido de estas disposiciones europeas. Lo referente a la libre circulación de trabajadores, en los términos en los que se haya definida en el Tratado Constitutivo CE, se encuentra plasmado en la Ley 17/ 1993, de 23 de diciembre, modificada por la Ley 55/1999, de 29 de diciembre, y por los Reales Decretos 800/1995, de 19 de mayo, y 543/2001, de 18 de mayo.
} 
Binsbergen $^{4}$, que, en ausencia de reglas específicas, éstos tenían directamente, según el Tratado, el derecho de establecerse y de ejercer actividades en el país miembro de su elección y el derecho a las mismas condiciones que los nacionales del país que les acogió sin que pudieran ser objeto de oposición ni por su nacionalidad ni por el lugar de su domicilio personal.

No obstante, persistía todavía un obstáculo: en ausencia de cualquier discriminación de nacionalidad, el acceso a ciertas actividades y su ejercicio quedan a menudo subordinadas a garantías de honorabilidad y de conocimientos prácticos o teóricos que son objeto de títulos o certificados que varían de un país miembro a otro. Para eliminar ese obstáculo ${ }^{5}$, la UE ha aprobado una serie de resoluciones con el propósito de conseguir que los títulos y la experiencia profesional obtenidos en un país sean considerados válidos en toda la Unión. Así, desde la apertura del mercado común, la Comisión y el Parlamento han presentado al Consejo decenas de disposiciones destinadas a armonizar la formación y las condiciones de acceso a determinadas actividades. Este molesto trabajo de aproximación legal, a menudo bloqueado por las reticencias de uno u otro Estado miembro celoso de conservar unas políticas a veces seculares, ha permitido sin embargo conseguir el mutuo reconocimiento de diversas "profesiones reguladas" ${ }^{6}$ de carácter liberal (como la de médico, farmacéutico, enfermero, dentista, veterinario, comadrona, arquitecto y abogado) y otras profesiones u oficios (entre los que figuran los relacionados con el comercio minorista y mayorista, la construcción, la hostelería, el transporte, correos, telecomunicaciones, agencias de viajes, comercio y distribución de productos tóxicos, prendas de vestir y textiles, agencias y corredores de seguros, silvicultura y horticultura) ${ }^{7}$.

${ }^{4}$ - 21.06.1974 (Reyners 2/74) Recopilación 1974, p. 631; derecho de establecimiento; abogados; aplicabilidad directa del artículo 52 CE desde el final del período de transición (01.01.1970), la excepción prevista en el párrafo 1 del artículo 55 CE, relativa al ejercicio de la autoridad pública, debe limitarse a las actividades que implican por sí mismas una participación directa y específica en la autoridad pública; no puede considerarse como tales las actividades de consulta y asistencia jurídica o la representación y defensa de las partes ante los tribunales, incluso si la realización de estas actividades es objeto de un obligación o de una exclusividad establecidas por ley.

- 03.12.1974 (Van Binsbergen 33/74) Recopilación 1974, p. 1.299; libre prestación de servicios; aplicación directa del artículo 59 CE desde el final del período de transición (01.01.1970); aplicación de normas de interés general.

${ }^{5}$ No podía subsistir una Europa de dos velocidades: la de los asalariados, móvil y abierta, y la de los profesionales liberales o prestatarios de servicios, compartimentada y cerrada.

${ }^{6}$ Se entiende por profesión regulada aquella actividad o conjunto de actividades profesionales cuyo acceso, ejercicio, o una de las modalidades de ejercicio están subordinadas de manera directa o indirecta, en virtud de disposiciones legales, reglamentarias o administrativas a la posesión de determinadas cualificaciones profesionales; en particular al empleo de un título profesional.

${ }^{7}$ Recientemente se han reunido todas estas decisiones en una única Directiva (2005/36/CE), que recoge también el sistema general (dirigido a aquellas actividades profesionales que no cuentan con una reglamentación específica). Esta Directiva se refiere en la mayoría de los casos al reconocimiento de títulos o diplomas, para lo cual se aplican ciertos principios básicos. Los preceptos europeos fijan criterios profesionales mínimos y niveles equivalentes de conocimientos especializados para todos los Estados miembros, ya que los sistemas de enseñanza y de formación presentan aún diferencias importantes entre unos países y otros. La coordinación de legislaciones referentes a la profesión de abogados es, en comparación con las otras profesiones liberales, original. Por lo que continúa manteniendo una reglamentación aparte. La razón es que en el ámbito de la abogacía el reconocimiento no 
Para agilizar este proceso de reconocimiento, que en algunos casos llegaba a prolongarse durante largo tiempo -por ejemplo, el acuerdo para los arquitectos tardó en cerrarse 17 años- y para evitar situaciones de injusticia entre las actividades que aún no disponían de la correspondiente directiva de armonización -permaneciendo cerradas al derecho de establecimiento o al de la libre prestación de servicios-, teniendo en cuenta que el Tratado prescribe la libertad de circulación para todas las actividades, la Comunidad ha dado vía libre a una directriz que desarrolla el denominado Sistema General de Reconocimiento de Cualificaciones Profesionales: la Directiva 2005/36/CE del Parlamento Europeo y del Consejo, de 7 de septiembre de 2005, relativa al reconocimiento de cualificaciones profesionales ${ }^{8}$.

Este texto fundamental permite a todo nacional de un Estado miembro ejercer su profesión reglamentada en otro Estado miembro distinto a aquel en que haya obtenido sus cualificaciones profesionales. Para ello se reconocen los siguientes títulos o certificados de formación y certificados de competencia que no estén recogidos en las disposiciones específicas relativas a las profesiones liberales o a determinadas profesiones o actividades profesionales reguladas:

- Un ciclo de estudios postsecundarios de una duración mínima de cuatro años a tiempo completo o su equivalente a tiempo parcial, cursado en una universidad o centro de enseñanza superior o en otra institución de nivel equivalente, y completado, en su caso, por la formación profesional establecida. (Título).

- Un ciclo de estudios postsecundarios de una duración mínima de tres años y no superior a cuatro a tiempo completo o su equivalente a tiempo parcial, cursado en una universidad, en un centro de enseñanza superior o en otro centro de un nivel de formación equivalente, y completado, en su caso, por la formación profesional indicada. (Título).

- Un ciclo de estudios postsecundarios de una duración mínima de un año a tiempo completo o su equivalente a tiempo parcial, una de cuyas condiciones de acceso sea, por regla general, la ter-

\footnotetext{
se refiere al título, sino a la condición de abogado. Mientras que la Directiva conjunta tiene como objeto facilitar el establecimiento y, dado el caso, la libre prestación de servicios, la directiva "abogados" sólo se refiere a la prestación de servicios. Para la mayor parte de actividades industriales, artesanales y comerciales, se ha liberado el acceso a la actividad de que se trata, y se han adoptado en caso necesario medidas destinadas a facilitar este acceso mediante el reconocimiento, en el país de acogida, de la experiencia profesional adquirida frecuentemente durante cierto número de años en el país de origen.

${ }^{8}$ Diario Oficial n. ${ }^{\circ}$ L 255 de 30/09/2005, pp. 22-142. Esta normativa ha venido a refundir las tres Directivas existentes anteriormente: 89/48/CEE y 91/51/CEE del Consejo, y la 1999/42/CE del Parlamento Europeo y del Consejo. La nueva Directiva se ajusta, como lo hacían las anteriores, perfectamente al concepto de subsidiariedad. Los Estados miembros siguen siendo responsables de determinar si una actividad profesional ha de estar regulada o no, y, en tal caso, qué nivel, estructura y contenido debe tener la enseñanza. El sistema general obliga a cada Estado miembro a crear unas estructuras que permitan el estudio individualizado de las solicitudes de reconocimiento, con las correspondientes garantías procedimentales y los mecanismos de compensación establecidos. El contenido de las anteriores ordenanzas que regulaban el sistema general, y que apenas difiere de la normativa hoy vigente, se encuentra incorporado al ordenamiento español mediante el Real Decreto 1665/1991, de 25 de octubre, modificado por los siguientes Reales Decretos: 767/1992, de 26 de junio (derogado por el Real Decreto 178/2003, de 14 de febrero); 2073/1995, de 22 de diciembre; 1754/1998, de 31 de julio; 411/2001, de 20 de abril; y 253/2003, de 28 de febrero.
} 
minación del ciclo de estudios secundarios exigido para optar a la enseñanza universitaria o superior, o una formación escolar equivalente de segundo nivel secundario, y completado, en su caso, por una formación profesional determinada. (Título).

- Un ciclo de estudios secundarios de carácter general o técnico o profesional, y completado, en su caso, por el periodo de prácticas o la práctica profesional que se requiera. O bien un período de prácticas o de ejercicio profesional que se precise además de ese ciclo de estudios secundarios (Certificado).

- Un ciclo de formación general de nivel de enseñanza primaria o secundaria que acredite que su titular posee conocimientos generales. O una formación que no forme parte de un certificado o título -como los anteriormente descritos-. O un examen específico sin formación previa, o bien el ejercicio a tiempo completo de la profesión en un Estado miembro durante tres años consecutivos o durante un periodo equivalente a tiempo parcial en el trascurso de los diez últimos años (Certificado de competencia).

Estos títulos y certificados de formación y certificados de competencia acreditarán que su titular posee las cualificaciones profesionales necesarias para acceder a una profesión regulada en un determinado Estado miembro o para ejercerla. Habrán de ser expedidos por una autoridad competente en un Estado miembro con arreglo a las disposiciones legales, reglamentarias o administrativas de dicho Estado.

Por esta razón, ningún país miembro -en el cual una profesión regulada o su ejercicio estén supeditados a la posesión de un título, certificado o certificado de competencia- podrá denegar a un nacional de otro país miembro el acceso a dicha profesión o su ejercicio en las mismas condiciones que a sus nacionales, alegando insuficiencia de cualificación:

a) Si el solicitante está en posesión del título, certificado o certificado de competencia-que acredite un nivel de cualificación profesional como mínimo equivalente al nivel inmediatamente anterior al exigido en el Estado miembro de acogida- prescrito por otro Estado miembro -donde también está regulada- para acceder a esa profesión o ejercerla en su territorio (en este caso no se podrán exigir dos años de experiencia profesional demandados en el párrafo siguiente).

b) Si el solicitante ha ejercido a tiempo completo dicha profesión durante dos años, o durante un periodo equivalente a tiempo parcial, en el curso de los diez años anteriores en otro Estado miembro que no regule esta profesión, siempre y cuando esté en posesión de uno o varios certificados de competencia o uno o varios títulos o certificados de formación que respondan a las características de los que anteriormente fueron mencionados -que acrediten un nivel de cualificación profesional como mínimo equivalente al nivel inmediatamente anterior al exigido en el Estado miembro de acogida-. Es preciso, además, probar que se ha ejercido en el Estado miem- 
bro de origen la misma profesión que se desea practicar en lo sucesivo en el Estado miembro de acogida. La dificultad en definir la profesión se debe al hecho de que, en teoría, la profesión no está regulada, en el sentido que señala la directiva. Habrá que examinar cuáles eran las actividades efectivamente ejercidas por el interesado durante los dos años en cuestión ${ }^{9}$.

c) Si el solicitante estuviera en posesión de un título que acredite que ha cursado con éxito una formación de nivel postsecundario de una duración mínima de un año, aunque en el Estado miembro de acogida el acceso a dicha profesión esté supeditada a la posesión de un título que sancione una formación de enseñanza superior o universitaria de una duración de cuatro años.

d) Si el solicitante hubiera adquirido su título en un país no miembro de la Unión, y dicho título hubiera sido ya reconocido en un Estado miembro, y en este último hubiera ejercido la profesión durante dos o tres años, según el caso, el mencionado título podrá ser reconocido en el Estado de acogida.

La Directiva basa el reconocimiento mutuo de los títulos en el principio de la recíproca confianza entre Estados miembros. Sin embargo, el Estado miembro de acogida puede exigir compensaciones en caso de diferencias importantes entre las formaciones:

- Cuando la duración de éstas presente diferencias que excedan de un año.

- Cuando la formación recibida corresponda a materias sustancialmente distintas ${ }^{10}$ de las que cubre el título de formación exigido en el Estado miembro de acogida.

- Cuando la profesión regulada en el Estado miembro de acogida abarque una o varias actividades profesionales reguladas que no existan en la profesión correspondiente en el Estado miembro del solicitante, y tal diferencia esté caracterizada por una formación específica exigida en el Estado miembro de acogida y relativa a materias sustancialmente distintas de las cubiertas por el certificado de competencia o el título de formación que el solicitante alega.

En tales supuestos, el peticionario podrá elegir entre realizar un período de prácticas durante tres años como máximo, impartido por un profesional responsable ${ }^{11}$, o someterse a una prueba de aptitud

\footnotetext{
${ }^{9}$ Un problema similar puede producirse cuando en el Estado miembro de origen la profesión esté regulada solamente mediante un título protegido; entonces se hace necesario averiguar si las actividades ejercidas con arreglo a dicho título corresponden a las que están reguladas en el Estado miembro de acogida.

${ }^{10}$ Las materias cuyo conocimiento sea fundamental para el ejercicio de la profesión y en las cuales la educación recibida por el migrante presente diferencias importantes de duración o contenido respecto a la formación exigida en el Estado miembro de acogida.

11 “"Período de prácticas», el ejercicio de una profesión regulada en el Estado miembro de acogida bajo la responsabilidad de un profesional cualificado, eventualmente acompañado de una formación complementaria. Este período de prácticas supervisadas será objeto de una evaluación. Las modalidades del período de prácticas y de su evaluación así como del estatuto del migrante en prácticas serán determinados por la autoridad competente del Estado miembro de acogida." (Directiva 2005/36/CE, artículo 1, letra g).
} 
que abarque la totalidad o parte de las materias que falten ${ }^{12}$. A título excepcional, el Estado miembro de acogida podrá ejercer esta elección e imponer bien un período de prácticas o bien una prueba de aptitud $^{13}$. Así ocurre con aquellas profesiones cuyo ejercicio exige un conocimiento preciso del Derecho nacional, y en determinadas profesiones sanitarias. Por otro lado, se deberá tener en cuenta, si procede, los conocimientos adquiridos por el peticionario en el transcurso de su experiencia profesional adquirida en un Estado miembro o en un tercer país. El examen de dicha práctica podrá reducir o incluso suprimir el citado requisito compensatorio ${ }^{14}$.

Los beneficiarios del reconocimiento de sus cualificaciones profesionales deberán poseer los conocimientos lingüísticos necesarios para el ejercicio de la profesión en el Estado miembro de acogida.Cuando se supedite, por parte de la autoridad competente del Estado miembro de acogida, "el acceso a una profesión regulada a la presentación de pruebas relativas a la honorabilidad, la moralidad o la ausencia de quiebra, o que suspenda o prohíba el ejercicio de dicha profesión en caso de falta profesional grave o de infracción penal, dicho Estado miembro aceptará, como prueba suficiente para aquellos nacionales de los Estados miembros que deseen ejercer dicha profesión en su territorio, la presentación de documentos expedidos por autoridades competentes del Estado miembro de origen o procedencia que demuestren el cumplimiento de tales requisitos" (Directiva 2005/36/CE, anexo VII, apartado 1, letra d) ${ }^{15}$. La situación es la misma en caso de que sea necesario presentar un documento o certificado relativo a la salud física o psíquica.

12 "«Prueba de aptitud», el control realizado exclusivamente sobre los conocimientos profesionales del solicitante, efectuado por las autoridades competentes del Estado miembro de acogida y que tiene por objeto apreciar la aptitud del solicitante para ejercer en dicho Estado miembro una profesión regulada. Para permitir dicho control, las autoridades competentes establecerán una lista de las materias que, sobre la base de una comparación entre la formación requerida en su Estado y la recibida por el solicitante, no estén cubierta por el diploma u otros títulos de formación que posea el solicitante.

En la prueba de aptitud deberá tenerse en consideración que el solicitante es un profesional cualificado en el Estado miembro de origen o de procedencia. La prueba versará sobre materias a elegir entre las que figuren en la lista y cuyo conocimiento sea una condición esencial para poder ejercer la profesión en el Estado miembro de acogida. Dicha prueba podrá incluir asimismo el conocimiento de la deontología aplicable a dichas actividades de que se trate en el Estado miembro de acogida.

Las modalidades de la prueba de aptitud y el estatuto de que goce en el Estado miembro de acogida el solicitante que desee prepararse para la prueba de aptitud en dicho Estado serán determinadas por las autoridades competentes de dicho Estado miembro." (Ibíd., artículo 1, letra h).

${ }^{13}$ En tales supuestos dicho Estado informará de la cuestión con antelación a los demás Estados miembros y a la Comisión, justificando de manera adecuada esta excepción. No obstante, la Comisión puede considerar en un plazo de tres meses que tal medida no es pertinente.

${ }^{14}$ Para eliminar estas barreras que generan las diferencias existentes entre los distintos procedimientos formativos, la UE ha iniciado un proceso de convergencia entre los sistemas nacionales de educación superior que permitirá desarrollar un espacio europeo común a partir de 2010.

${ }^{15}$ Cuando los documentos no puedan ser expedidos por las autoridades competentes del Estado miembro de origen o procedencia serán sustituidos por una declaración jurada o solemne, según los casos. La autoridad competente del Estado miembro de acogida podrá exigir que no hayan transcurrido más de tres meses desde la fecha de expedición de los documentos o certificados. 
Por el contrario, si el acceso a una determinada profesión no está regulado en el Estado miembro de acogida, no es necesario solicitar el reconocimiento de la titulación que nos acredite como personas cualificadas para el desempeño de la misma, y puede iniciarse el ejercicio en las mismas condiciones que los ciudadanos del país, con los mismos derechos y obligaciones.

La Directiva instituye garantías de procedimiento: el Estado miembro de acogida deberá resolver las peticiones en un plazo máximo de tres meses (que podrá prorrogarse un mes en determinados casos); deberá motivar sus decisiones y prever posibilidades de recurso de justicia. Además, se establece un mecanismo de cooperación con la creación, en la Comisión Europea, de un grupo de coordinadores designados por los Estados miembros y encargados de promover la uniformidad de aplicación del sistema general.

Esta Directiva tiene fuerza vinculante con respecto a los Estados miembros por lo que se refiere al resultado que hay que alcanzar, pero da libertad para elegir las formas y los medios para su ejecución. En caso de conflicto entre una directiva y una disposición nacional, será la primera la que prevalecerá, y las personas interesadas así podrán hacerlo valer ante los tribunales nacionales. Las instituciones comunitarias no tienen, sin embargo, la facultad de anular la decisión administrativa de una autoridad nacional. Las sentencias del Tribunal de Justicia de la UE se limitan a declarar el incumplimiento de las obligaciones de un Estado, bien por aplicar incorrectamente el Derecho comunitario bien por promulgar una legislación nacional incompatible con éste. Las autoridades del Estado implicado deberán modificar las decisiones individuales que hubieran tomado con arreglo a una legislación o práctica condenada por el Tribunal.

\section{La Unión Europea y la profesión periodística: posición actual}

A finales de 1989, ante la cercanía de la fecha señalada por el Acta Única Europea para el comienzo de un mercado unificado de fronteras permeables por el que circulasen libremente las personas, los bienes y los servicios, representantes de asociaciones profesionales y sindicatos de periodistas de los distintos países miembros se reunieron por primera vez para cambiar impresiones acerca de cómo estaba estructurada la profesión en cada uno de ellos, y tratar de unificar posturas sobre modos de acceso, nivel de formación, reconocimiento y emisión del carné profesional, sindicación o agrupación, defensa de derechos, acuerdos laborales, etc., que permitieran homogeneizar las condiciones del ejercicio de las actividades periodísticas de cara a garantizar la libre circulación de estos profesionales.

A esa reunión, celebrada en Pamplona del 14 al 17 de noviembre bajo el nombre de "I Encuentro con Periodistas de la CEE”, acudieron representantes del Parlamento y la Comisión Europeas. Tras el

\footnotetext{
${ }^{16}$ La invitación corrió a cargo de la Federación de Asociaciones de la Prensa de España (FAPE) que celebraba simultáneamente su XLIX Asamblea.
} 
fracaso del último proyecto de Directiva ${ }^{17}$, la postura adoptada por los organismos comunitarios se iba a caracterizar por la ausencia de actuaciones directas. Así se manifestaba la representante de Bruselas, Nicole Cauchie, en el encuentro de Pamplona:

no hay y no habrá una directiva particular para la libre circulación de periodistas. Pienso que esto tranquilizará a bastantes representantes que están aquí que tenían la voluntad de uniformización de las instituciones europeas; así que no habrá ninguna directiva que se aplique específicamente a los periodistas.

La filosofía que presidía la libre circulación de personas era el reconocimiento mutuo de los diplomas por profesión, previamente con la coordinación y la armonización de las condiciones de formación; en realidad, se trataba precisamente de una voluntad de uniformización y con arreglo a un tipo de modelo; desde luego, era un método que tenía sus ventajas y sus inconvenientes.

Entre los inconvenientes, uno era la larga duración de los trámites; [...] Se ha visto por tanto que era una tramitación que llevaba directamente a un callejón sin salida si se quería acelerar el movimiento en el marco del objetivo 92, y ahora hay lo que se conoce como un nuevo enfoque mucho más pragmático que trata de dar una respuesta muy directa a las necesidades de los profesionales de poder ejercer su profesión fuera de su país; por lo tanto, existe un sistema general de reconocimiento mutuo, sin condiciones previas, de coordinación de las condiciones de acceso a la profesión.

¿Qué significa esto? Significa que no habrá uniformización y que sólo se dará la coexistencia de los sistemas existentes en los diferentes Estados miembros. No significa esto que va en contra del principio de libre establecimiento y de la libre prestación de personas en los diferentes países; el principio, en este aspecto, es el de la asimilación del emigrante en el país de acogida, o sea, que cada Estado miembro tiene que aplicar un sistema de comprobación para cerciorarse precisamente que la formación corresponde y las exigencias profesionales son compatibles. Es toda la diferencia que hay entre lo que había adquirido aquél que quiere ejercer su profesión en otro país y lo que se requiere en dicho país para ejercer la profesión.

[...] Si no hay o si no habrá una directiva relativa a los periodistas, esto no quiere decir que la Comunidad y la Comisión se desentiendan de la cuestión, debido precisamente a la estrategia multinacional de las agrupaciones de prensa.

En la Comisión se piensa, en general, que dicha estrategia multinacional requiere unas organizaciones profesionales fuertes, debido a todo lo que ocurre en este momento y se han visto en la necesidad de examinar más concretamente lo que pasaba con la prensa escrita y organizar un encuentro de profesionales de los Estados miembros, al más alto nivel, en lo que se conoce como "Los Congresos de la Prensa Escrita", inspirándose algo en el modelo de lo que ocurrió a finales de septiembre y principios de octubre en París en lo audiovisual, ya que a éste, normalmente, se le podía considerar como un producto industrial, aunque la ambigüedad del producto, industrial y cultural al mismo tiempo, fue reconocida oficialmente. Los productos audiovisuales no se benefician de la libre circulación de mercancías. Se ha reconocido su carácter específico, y creo que se están dando los mismos pasos en lo relativo a la prensa y a la información. [...] Por lo tanto, que sea una represen-

${ }^{17}$ Para el campo de la actividad periodística, la entonces CEE, redactó dos propuestas de directiva: una en 1964 y otra en 1972. Ninguna de ellas vería la luz. La segunda no fue tan siquiera debatida. 
tación en una federación europea de periodistas o en la federación internacional de periodistas, que ha demostrado su eficacia en varios ámbitos, de momento le corresponde naturalmente a cada una de las organizaciones profesionales el decidir y elegir su camino, aunque se nota ya la necesidad de una organización estructurada, coherente, tanto a nivel nacional como a nivel internacional europeo, para tener unos interlocutores con los empresarios de prensa y también con las autoridades públicas con el fin de agotar, especialmente, todos los recursos posibles, ya sea en el marco jurídico nacional, ya sea en el marco jurídico internacional en el Tribunal Europeo y también, ìpor qué no?, en el Tribunal de Derechos Humanos, el tribunal que depende del Consejo de Europa en Estrasburgo.

[...] para las profesiones médicas y para los arquitectos, [...] la tramitación duró entre 10 y 17 años; para unas profesiones que están reglamentadas, más o menos, de la misma forma en los 12 Estados miembros.

Si se toma en cuenta las diferentes condiciones de acceso a la profesión de periodista en los diferentes países miembros, no había ninguna esperanza, ni mucho menos, de conseguir un acuerdo sobre una Directiva de libre circulación de periodistas. [...] la Comisión requiere unas organizaciones profesionales fuertes, estructurales, sólidas, representativas. En efecto, la pelota está ahora en vuestro campo, en el campo de la FIJ (Sin firma, 1990: 1-16, páginas centrales).

La posición de la por entonces Comunidad Europea era clara: no había prevista a nivel comunitario ninguna regulación sobre este tema y, por tanto, deberían ser las organizaciones profesionales las que mediante acuerdos de normalización de condiciones de acceso, de formación de periodistas, de nivel de retribuciones, etc., fueran sentando las bases de una uniformidad europea de la profesión.

Con anterioridad, a principios de la década de los ochenta, en contestación a una pregunta escrita formulada por la eurodiputada Sra. Squarcialupi, a propósito del secreto profesional y del acceso a las fuentes de información de los periodistas de los Estados miembros de la Comunidad Europea, el Sr. Narjes, en nombre de la Comisión manifestaba lo siguiente:

La Comisión no dispone de una información exhaustiva en lo concerniente a la reglamentación del secreto profesional de los periodistas de los Estados miembros porque no tiene intención de proponer en un futuro previsible una armonización de las reglas de los Estados miembros en la materia.

La Comisión tampoco tiene intención de proponer una coordinación de las disposiciones de los Estados miembros relativas al acceso de los periodistas a las fuentes de información en la Comunidad.

La Comisión estima, en efecto, que es necesario y suficiente para el buen funcionamiento del Mercado Común que todo periodista, nacional de un Estado miembro, puede ejercer sus actividades en otro Estado miembro con los mismos derechos y los mismos deberes que sus colegas del país de acogida. Que la Comisión sepa, estas condiciones se respetan en todos los Estados miembros ${ }^{18}$.

A este primer contacto de periodistas europeos celebrado en Pamplona le siguieron otros en Cerdeña, Bruselas y Santander. Los progresos fueron escasos. En julio de 1991, promovido por las Institu-

${ }^{18}$ Cuestión escrita N. ${ }^{\circ} 1168 / 81$, de Sra. Squarcialupi a la Comisión de las Comunidades Europeas (22 de octubre de 1981). Respuesta del Sr. Narjes en nombre de la Comisión (1 de diciembre de 1981). Véase Diario Oficial n. ${ }^{\circ}$ C 12/19, de 18/01/1982. 
ciones comunitarias -tal y como había señalado Nicole Cauchie casi dos años antes en Pamplona-, tuvo lugar el "Congreso de la Prensa Escrita" (Assises de la Presse Escrite), un foro de debate entre sindicatos y empresarios de prensa escrita, terminado "como el rosario de la aurora" entre acusaciones y descalificaciones mutuas. En marzo de 1992, a propuesta de la Agrupación de Periodistas de UGT (AGP-UGT) -miembro de la Federación Internacional de Periodistas-, se organizó en Bruselas una conferencia específica para debatir quién era periodista y que llevó por título "El Estatuto del periodista profesional en Europa". En ninguno de estos encuentros fue posible avanzar más allá de las tesis que defendían que "el acceso a la profesión debe ser libre. El nivel de formación de los futuros periodistas debe ser el más elevado posible, pero un diploma, una licenciatura universitaria o un certificado de formación clásica, no debe ser la condición «sine qua non» para el acceso a la profesión. La experiencia y la cualificación profesional, son igualmente válidas"”19.

La situación no ha cambiado en la actualidad. Y la Comunidad (hoy Unión) Europea tampoco ha modificado su postura a lo largo de estos años. En 1997, emití una consulta a la Secretaría General del Consejo de la Unión Europea para conocer si había variado en algo su posición. Remitieron mi pregunta a la Dirección General XV de la Comisión Europea "Mercado Interno y Servicios Financieros. Propiedad intelectual e industrial. Libertad de establecimiento y libre prestación de servicios, especialmente en las profesiones reguladas, los media"20. La respuesta, que apenas tardó un par de meses en llegarme, fue concisa y sin lugar a la ambigüedad: "cada país es libre para regular o no el ejercicio de la profesión en sus territorios y para determinar el nivel de las aptitudes requeridas para acceder a la profesión. La Comisión Europea no tiene intención de proponer medidas que armonicen las condiciones de acceso y ejercicio de esta profesión. La ley comunitaria requiere que la normativa nacional respete el principio de no discriminación entre nacionales comunitarios". Interpelada también la Comisión acerca de posibles quejas presentadas por periodistas de la Unión, que ante su deseo de establecerse en otro país miembro y ejercer allí su profesión se hubieran encontrado con alguna dificultad, la contestación fue asimismo negativa (o, por lo menos, no tenía constancia de alguna reclamación al respecto). Reiteradas nuevamente dichas consultas en 2003 a los órganos pertinentes, las respuestas no divergieron de las anteriormente obtenidas. La situación, por tanto, persiste en la actualidad.

Tampoco es del interés de los organismos comunitarios definir un estatuto europeo del periodista, una carta de prensa europea, pues esta labor es competencia de cada Estado miembro, y cualquier acuerdo comunitario sólo puede alcanzarse con el consentimiento unánime de todos ellos y el respaldo

${ }^{19}$ Extracto de la Resolución de la Conferencia “El Estatuto del periodista profesional en Europa" (Bruselas, marzo de 1992), referida por Alfonso Díez -ex presidente de la AGP-UGT- en un texto firmado en Madrid el 12 de julio de 1993, con el título “Modelos internacionales de acceso a la profesión periodística", que él mismo me facilitó en el verano de 1996.

20 "Internal Market and Financial Services. Intellectual and industrial property. Freedom of establishment and freedom to provide services, notably in the regulated professions, the media." 
del colectivo profesional. Sirva de ejemplo la réplica ofrecida por el Sr. Pinheiro, en nombre de la Comisión, al eurodiputado Sotiris Kostopoulos acerca de una posible elaboración de una directiva marco europea relativa a la garantía de la independencia de los periodistas y de los articulistas en todos los medios de comunicación:

La Comisión considera que la independencia de los periodistas y articulistas debe fundamentarse en las prácticas profesionales y normativas nacionales vigentes. Por consiguiente, no tiene intención de proponer ninguna directiva marco en este terreno, lo que por otro lado vulneraría el principio de subsidiariedad ${ }^{21}$.

\section{Consideraciones en torno a la libre circulación de periodistas en la Unión Europea}

No existen, en principio, serias dificultades para que un periodista de un Estado miembro pueda ejercer su profesión en otro Estado miembro de la UE. Pero será preciso analizar con mayor detenimiento esta situación para determinar si efectivamente esto es así.

La ausencia de condiciones previas al acceso a la profesión de periodista en los Estados miembros se debe al concepto, que comparten todos estos países, de que justamente la libertad de expresión y el derecho a la información, como principio fundamental de su organización política, exige la total libertad de acceso a los medios informativos, incluido el acceso profesional. Las variaciones en los sistemas de ingreso a la profesión en los países de la UE afectan a la forma, no al fondo de su concepto de libertad. Existen dos grandes grupos, la de los países donde es periodista quien lo desee, quien quiera otorgarse tal título a sí mismo, y la de los países que no imponen condiciones a priori, sino a posteriori para la concesión definitiva de la categoría profesional (el acceso es libre después de demostrar que se trabaja como periodista).

Dentro del primer grupo se encuentran: Alemania, Austria, Chipre, Eslovaquia, Eslovenia, España ${ }^{22}$, Estonia, Finlandia, Hungría, Irlanda, Letonia, Lituania, Malta, Países Bajos, Polonia, Reino Unido, Re-

${ }^{21}$ Pregunta escrita E-2338/93, de Sotiris Kostopoulos a la Comisión (1 de septiembre de 1993). Respuesta del Sr. Pinheiro en nombre de la Comisión (19 de noviembre de 1993). Véase Diario Oficial n. ${ }^{\circ}$ C 6, 9/01/1995, p. 3.

${ }^{22}$ En nuestro país se está debatiendo por las Cortes Generales una Proposición de Ley sobre un Estatuto del periodista profesional. En dicha proposición, figura la creación de un Consejo Estatal de la Información que otorgará carnés profesionales a aquellos que acrediten estar ejerciendo la profesión. Lo que no queda claro es qué pasará con los que no logren el mencionado carné: si sólo se verán privados de ostentar el calificativo "profesional» y podrán desempeñar del mismo modo "tareas de información de actualidad e interés público" (como reza la proposición) o, además, estas últimas les estarán asimismo vetadas. La FAPE, que se ha escindido del Foro de Organizaciones de Periodistas (FOP, organismo que ha redactado la Proposición de Ley), ha presentado al Congreso de Diputados un modelo de Estatuto profesional alternativo. En esta segunda propuesta, el periodista sería aquél que ostentara un título académico expedido por una facultad de Periodismo (o denominación equiparable) o por las extintas escuelas de Periodismo, y desempeñe profesionalmente labores periodísticas. Tampoco se hace hincapié en la exclusividad de competencias. Por lo que de aprobarse cualquiera de las dos propuestas, España pasaría a pertenecer al segundo grupo, en parecida situación a la que aplican Bélgica, Francia y Luxemburgo. 
pública Checa y Suecia ${ }^{23}$. Los empresarios contratan para realizar las tareas de periodista a quien consideren que, a su juicio, posee condiciones para ello. El hecho de ejercer como trabajo principal y retribuido -bien como empleado fijo o libremente- las labores de obtención y elaboración de información y de opinión para difundirla o comunicarla públicamente a través de un medio de comunicación, les convierte automáticamente en periodistas. No se concede ningún carné de prensa a los periodistas profesionales -salvo el que cada asociación, sindicato o empresa quiera suministrar a modo de seña de identidad para facilitar la labor profesional ${ }^{24}$.

En el segundo grupo se encuadran Bélgica, Francia, Luxemburgo (donde el uso y disfrute del título de periodista profesional está regulado por Ley), Italia y Portugal (donde además del título también está protegida legalmente la actividad profesional). La contratación de un periodista por una empresa de información es totalmente libre, pero en este segundo grupo de países el nuevo miembro del gremio deberá reunir una serie de requisitos para recibir su acreditación definitiva como periodista profesional. Entre las características esenciales que regulan el acceso a la profesión periodística en estos Estados podemos destacar las siguientes: la mayoría de edad; la exigencia de una dedicación previa, en torno a los dos años (que puede verse reducida dependiendo del tipo de estudios que acredite el candidato, o incluso sustituida por una formación teórico-práctica específica en Periodismo impartida por una Escuela reconocida por las organizaciones profesionales), continua y remunerada que suponga el principal medio de vida ${ }^{25}$; y disfrutar de plenos derechos civiles. La concesión de las acreditaciones corresponde bien a los propios periodistas (tal es el caso de Italia y Portugal), o bien a una comisión paritaria compuesta, de un lado, por representantes de las organizaciones profesionales y sindicatos de periodistas, y de otro, por representantes de las agrupaciones de empresarios de comunicación (como ocurre en Bélgica, Francia y Luxemburgo); que no podrán actuar nunca con criterios de cooptación u otros parecidos que supongan la introducción de restricciones de carácter corporativista.

Dinamarca y Grecia cabría clasificarlos dentro del primer grupo, pues en principio la ley no recoge la exigencia de ningún requisito a posteriori para ser considerado periodista y, sobre el papel, el acceso es libre. Sin embargo, la fuerza que en estos países tienen las asociaciones de periodistas hace que se respeten las condiciones que éstas han acordado para el acceso a la actividad periodística. Dinamarca es el único país de la UE donde se exige la Licenciatura en Periodismo, bajo el exclusivo control de la Federación de la Prensa. De todos modos, y aunque cada vez son menos, también se puede ser periodista por el simple ejercicio de la actividad. Por su parte, en Grecia, el sindicato de periodistas tiene estipulados requisitos muy similares a los que hemos señalado para el segundo grupo de países.

\footnotetext{
${ }^{23}$ Próximamente habrá que incluir dentro de este grupo a Bulgaria y Rumania. Recordemos que Islandia, Liechtenstein, Noruega y Suiza también serían susceptibles de formar parte del mismo, merced a los acuerdos firmados con la UE.

${ }^{24}$ El carné de periodista profesional que en España concede la FAPE es meramente testimonial.

${ }^{25}$ En Italia el único medio de vida, pues la actividad periodística debe realizarse con dedicación exclusiva.
} 
Prohibida, desde 1970, cualquier discriminación de nacionalidad entre ciudadanos de la Unión en materia de acceso al empleo, toda persona tiene el derecho de establecerse y de ejercer actividades en el país miembro de su elección en las mismas condiciones que los nacionales del país de acogida. Lo que en principio nos llevaría a presuponer que, en el caso de los periodistas, ante la falta de una directiva específica destinada a homogeneizar la formación y las condiciones de acceso, bastaría con adaptarse a los requisitos que para ejercer el Periodismo tiene cada país de la UE.

La ausencia de formalidades en la mayoría de Estados miembros reduce considerablemente las complicaciones que la libre circulación de estos profesionales pudiera generar. Sin embargo, las dificultades surgen con aquellos países que protegen legalmente el título de periodista profesional o también el ejercicio de la actividad periodística, que únicamente puede ser desempeñada por aquellos que han obtenido el título profesional de periodista. Para solventar los posibles problemas y dudas que pudieran originarse en estos Estados miembros (recordemos que son Francia, Bélgica, Italia, Luxemburgo y Portugal), podemos acudir a lo establecido en la Directiva 2005/36/CE, aunque en los apartados y anexos en los que se hace relación a profesiones o actividades profesionales específicas no figura el Periodismo ${ }^{26}$. Por lo que cabe deducir, en principio, la aparente falta de consenso de los diferentes Estados miembros a la hora de considerar a la de periodista una profesión o actividad profesional regulada a la luz de lo indicado en la mencionada directriz.

Tras un detallado análisis observamos que, en relación con la Directiva, Italia y Portugal serían los únicos países de la UE donde el Periodismo podría constituir una profesión regulada. En el artículo 3 (letra a) se especifica que la profesión regulada es "la actividad o conjunto de actividades profesionales cuyo acceso, ejercicio o una de las modalidades de ejercicio están subordinadas de manera directa o indirecta, en virtud de disposiciones legales, reglamentarias o administrativas, a la posesión de determinadas cualificaciones profesionales; en particular, se considerará modalidad de ejercicio el empleo de un título profesional limitado por disposiciones legales, reglamentarias o administrativas a quien posea una determinada cualificación profesional”. El epígrafe siguiente (letra b) indica a su vez que ha de entenderse por cualificaciones profesionales "las cualificaciones acreditadas por un título de formación, un certificado de competencia tal como se define en el artículo 11, letra a), inciso i), y/o una experiencia profesional" 27 .

${ }^{26}$ Los ciclos de formación que figuran en la Directiva podrán modificarse mediante petición motivada por cualquier Estado miembro interesado y dirigida a la Comisión. A esta petición deberá añadirse todo tipo de información útil y, en particular, el texto de las disposiciones de derecho nacional pertinentes. El Estado miembro solicitante informará igualmente a los demás Estados miembros. La Comisión adoptará una resolución asistida por un Comité compuesto por representantes de los Estados miembros y presidido por el representante de la Comisión. La decisión última, no obstante, corresponde al Consejo que, por mayoría cualificada, acepta o rechaza la petición del Estado miembro en cuestión.

${ }^{27}$ Bélgica, Francia y Luxemburgo quedarían fuera de esta relación al proteger legalmente sólo el título profesional (el cual sólo requiere un certificado de competencia), pero no así la actividad que a través de éste se pudiera desempeñar. Es decir, que 
El conjunto de formalidades legales que es preciso reunir para poder ser habilitado como periodista profesional en Portugal, bien pueden ser calificadas de certificado y/o certificado de competencia -según los casos- en los términos señalados por la Directiva europea ${ }^{28}$. La situación en Italia presenta una peculiaridad respecto a la circunstancia portuguesa. De los requisitos que es preciso reunir según la Ley italiana para acceder al Periodismo y ejercer con categoría de profesional, sólo la superación del examen de Estado o prueba de idoneidad profesional organizada por el Colegio de Periodistas otorgaría tan acreditado privilegio. La satisfacción del resto de exigencias (el praticantato, por ejemplo, constituiría a efectos de la Directiva un certificado) únicamente permiten estar en disposición de presentarse al examen de Estado (o en tal caso a trabajar como publicisti), mediante el cual -y sólo si se supera satisfactoriamente- es posible ser admitido como periodista profesional. Este examen de Estado o prueba de idoneidad profesional sí es una condición ineludible. Y bien podría entenderse como un certificado de competencia -en los términos señalados por la Directiva-, que busca garantizar que en el aspirante concurren los conocimientos básicos necesarios acerca de la actividad profesional, así como de las leyes jurídicas y normas ético-deontológicas que le afectan ${ }^{29}$. Con lo que tanto el Sindicato de Periodistas de Portugal como el Colegio Profesional de Periodistas de Italia -para los casos de derecho de establecimiento especialmente- están en su derecho de exigir a los inmigrantes de otro país miembro de la UE las mismas condiciones que exigen para los ciudadanos portugueses e italianos.

Ahora bien, y siguiendo con lo estipulado en la Directiva, aquellos ciudadanos de la UE que dispongan asimismo de un certificado o certificado de competencia exigido por otro Estado miembro para acceder a la misma profesión; o bien acrediten cualificaciones obtenidas en otros Estados miembros, ya mediante cualquier otra título de formación o incluso a través del ejercicio efectivo de la misma, y que ofrezcan garantías equivalentes a las exigidas por las disposiciones legales, reglamentarias o administrativas del Estado miembro de acogida, no podrá serles denegado el acceso a dicha profesión o a su ejercicio en las mismas condiciones que sus nacionales, por falta de cualificación. Con lo cual se interpreta que, en estos casos, se está exento de tener que concurrir a otra formalidad añadida (pues tanto el título de formación como la experiencia práctica son pruebas suficientes de esa aptitud profesional que tratan de asegurar el certificado y el certificado de competencia). Por lo que todo aquel que cumpla

aquellos que no han logrado tal distinción nominal si pueden, en cambio, ejercer como tales, aunque sin denominarse periodistas profesionales.

${ }^{28}$ Para un exacto conocimiento de dichas exigencias véase REAL, 2003: 363-371; y la dirección electrónica del sindicato portugués de periodistas (Sindicato dos Jornalistas): www.jornalistas.online.pt

${ }^{29}$ Si bien, igualmente es preciso tener en cuenta que una vez superado este examen de Estado, es necesario mantener la dedicación exclusiva a la actividad periodística para seguir disfrutando de su condición profesional. En caso contrario, y hasta que ésta se restablezca, sería degradado a la categoría de publicisti. No cabe duda de que se trata de una profesión regulada un tanto especial. Para completar esta información puede consultarse REAL, 2003: 344-363. También se recomienda acudir a la dirección electrónica del Colegio Profesional de Periodistas italianos (Ordine dei Giornalisti): www.odg.it 
con el resto de requisitos podrá ser dado de alta en el Sindicato o Colegio Profesional de Periodistas y obtener su reconocimiento como periodista profesional. De lo contrario, si el interesado no confirma tales cualificaciones, tendrá que someterse a las disposiciones legales, reglamentarias o administrativas que estipula el país miembro de acogida. Aunque, también conviene señalarlo, los Estados italiano y portugués si al examinar los conocimientos del solicitante no los encontraran plenamente satisfactorios podrían exigirle, en su defecto, optar por un período de prácticas de adaptación o una prueba de aptitud para aquellas materias en las que presente una formación deficitaria.

En el resto de Estados miembros de la UE, al no constituir el Periodismo una profesión regulada en el sentido que establece la mencionada Directiva, los ciudadanos comunitarios que cuenten con una experiencia práctica suficiente en el campo del Periodismo, pueden iniciarse o ser contratados para el ejercicio del mismo sin que sea necesario solicitar ante la autoridad competente el reconocimiento de su cualificación profesional. Se parte del supuesto de que si una persona es apta para ejercer el Periodismo en un Estado miembro posee los suficientes conocimientos para practicar esa misma actividad en los demás países de la UE..., siempre y cuando un empresario quiera contratar sus servicios.

El problema sobreviene a la hora de comparar las definiciones que, en cada Estado miembro, se han acordado con más o menos consenso acerca de quién es periodista y qué tipo de actividad o actividades conlleva su ejercicio. Recordemos pues cuáles son esas definiciones, así como la estipulada por la Federación Internacional de Periodistas (FIP):

- Alemania: (Organizaciones profesionales). Periodista es quien participa en la elaboración y/o difusión de informaciones, opiniones y actividades recreativas en los medios de difusión mediante la palabra, la imagen, la televisión o cualquier combinación de estos medios de comunicación. Los periodistas trabajan como colaboradores fijos o libres para medios de difusión impresos (periódicos, revistas, periódicos publicitarios o producciones editoriales actuales), emisoras de radio (radio y televisión) y otros medios de difusión electrónicos (medios on- y offline, en la medida que se generen ofertas y servicios de carácter periodístico), agencias de noticias, servicios de prensa en los sectores económico, administrativo y social (trabajo con el público y comunicación intraempresarial), así como en el trabajo educativo-cultural y de asesoramiento en los medios de difusión. Entre los servicios periodísticos figuran principalmente la elaboración de informaciones verbales o gráficas mediante la indagación (colección y análisis), así como la selección y procesamiento de contenidos informativos, su adecuación creativa al medio específico (informe y comentario), la configuración y transmisión, además de actividades preparatorias relacionadas con la organización, la técnica y el personal.

- Bélgica: (Ley 30 de diciembre de 1963, artículo 1). Periodista profesional es aquel mayor de edad (21 años) no incurso en los casos previstos en el Código Penal que ejerce como profesión principal y retribuida el trabajo en un medio de información general (ya sea prensa escrita, hablada, tele- 
visada o filmada, o en una agencia de prensa), con una experiencia al menos de 2 años y no practica actividad publicitaria.

- Dinamarca: (Organización profesional). Periodista es aquel licenciado universitario en Periodismo inscrito en la Federación de la Prensa.

- España: (Organizaciones profesionales y Proposición de Ley del Estatuto del Periodista Profesional, artículo 1). Se aceptan tres vías de acceso: el licenciado en Periodismo o el diplomado por las antiguas Escuelas de Periodismo; el licenciado en cualquier otra titulación con dos años de experiencia en un medio de comunicación; todo aquel que, sin necesidad de una formación secundaria o universitaria, acredite cinco años de experiencia ininterrumpida en un medio de comunicación. La Proposición de Ley del Estatuto del Periodista Profesional, define al periodista profesional como todo aquel que tiene por ocupación principal y remunerada la obtención, elaboración, tratamiento y difusión por cualquier medio de información de actualidad, en formato literario, gráfico, audiovisual o multimedia, con independencia del tipo de relación contractual que pueda mantener con una o varias empresas, instituciones o asociaciones. Por su parte, la alternativa de la Federación de Asociaciones de la Prensa de España (FAPE) otorga esta condición a quién está en posesión de un título (licenciatura u otro para el que se requiera estar en posesión de una licenciatura) expedido por una facultad de periodismo, o denominación equiparable, de cualquier universidad española, así como de quién posea el título de periodista expedido por las extintas escuelas de periodismo. En el ánimo de diferenciar al periodista ejerciente del no ejerciente puntualiza que el titular de los derechos y deberes definidos en este Estatuto es el periodista que realiza profesionalmente tareas de información de actualidad e interés público, mediante una relación laboral por cuenta ajena o por cuenta propia.

- Francia: (Artículo 762.1 del Código de Trabajo). Periodista profesional es aquel que tiene por ocupación principal, regular y retribuida el ejercicio de su profesión en una o varias publicaciones diarias o periódicas o en una o varias agencias de prensa o en una o varias empresas de comunicación audiovisual ${ }^{30}$, que constituye la parte fundamental de sus ingresos. Son asimilados como periodistas profesionales los colaboradores directos de la redacción que se encuadran en las siguientes categorías: redactores-traductores, estenógrafos-redactores, redactores-correctores, redactores-diseñadores/dibujantes, redactores-fotógrafos y los reporteros de imágenes (“cameramen”), se excluyen de esta relación los agentes publicitarios, a los que desempeñen labores de relaciones públicas y a todos aquellos que únicamente aporten colaboraciones esporádicas u ocasionales.

${ }^{30}$ Esta parte no se contempla en el artículo citado, pero ha sido incluida para actualizar el concepto del profesional de la información por el convenio colectivo de periodistas, firmado por vez primera en noviembre de 1976 (modificado cada dos o tres años). 
- Grecia: (Organizaciones profesionales). Periodista es aquel mayor de edad que no ha incurrido en causas penales, que cuenta con un título mínimo de estudios elementales, ejerce de forma ininterrumpida la profesión desde hace 1, 3 ó 5 años (según los estudios previos con los que se cuenten) y ha superado una prueba de admisión.

- Italia: (Ley del Ordine dei Giornalisti de 3 febrero de 1963). Periodista es aquel mayor de edad (21 años), que no ha incurrido en condena penal que acarree la prohibición al acceso a la función pública, cuenta al menos con un título de enseñanza secundaria (o ha aprobado el examen de cultura general que exige el Ordine), ha efectuado un período de prácticas de 18 meses en un órgano informativo (o ha realizado el curso bienal de una Escuela de Periodismo reconocida por el Ordine, o bien acredita una diplomatura en Ciencias de la Comunicación siempre que se haya realizado posteriormente un Master de Periodismo de un año dedicado preferentemente a la práctica profesional, o, en su caso, ha cursado la especialidad de postgrado de dos años en "Ciencia del Editorial, de la Comunicación Multimedia y del Periodismo”), ejerce de forma retribuida, exclusiva y continua la profesión de periodista, ha superado una prueba de idoneidad y está inscrito en el Ordine.

- Luxemburgo: (Ley de 10 de diciembre de 1979 y reglamento de 1984). Periodista es: quien ejerce la profesión en un medio de información general (ya sea prensa escrita, hablada, televisada o filmada, o en una agencia de prensa), siendo mayor de edad, sin causas penales o civiles incompatibles, con una práctica de al menos 2 años y que no ejerce actividades publicitarias.

- Holanda/Países Bajos: (Asociación Holandesa de Periodistas). Periodista es aquel que, bien por vínculo de servicio, bien como independiente, dedica su actividad fundamental -hasta hacer de ello una profesión- a colaborar en la dirección o elaboración redaccional de: a) un diario, boletín de actualidad o revista, siempre que el contenido de los mismos conste de noticias, fotos u otras ilustraciones, reportajes o artículos; b) una agencia de prensa, dedicada a la elaboración de noticias, fotos u otras ilustraciones, reportajes o artículos, destinados a diarios, boletines, revistas, radio, televisión o cine; c) programas difundidos por radio o televisión, siempre que consten de noticias, reportajes, consideraciones o rúbricas de naturaleza informativa; d) películas, imágenes y sonido, siempre que dichos elementos proporcionen noticias, tengan un carácter documental o sean útiles para rúbricas de naturaleza informativa.

- Portugal: (Ley de 13 de enero de 1999). Periodista profesional es aquel mayor de edad que disfruta de plenos derechos civiles, ha completado al menos 12 años de enseñanza básica y secundaria, ha cumplido con aprovechamiento un período obligatorio de prácticas de 24 meses en un medio de comunicación (18 meses para aquel que cuenta con un título universitario y 12 si éste es en el área de la Comunicación social), ejerce el periodismo como ocupación principal, permanente y remunerada vinculado a una empresa informativa, al menos, durante cuatro años, y no desempeña 
funciones publicitarias o de relaciones públicas, policíacas, militares o gubernamentales. A continuación se define la actividad periodística como aquella centrada en el ejercicio de funciones de búsqueda, recogida, selección y tratamiento de datos, noticias u opiniones, a través de texto, imagen o sonido, destinados a la divulgación informativa en la prensa, por agencia informativa, en la radio, en la televisión o por otra forma de difusión electrónica. No constituye, sin embargo, actividad periodística el ejercicio de estas funciones cuando sean desempeñadas al servicio de publicaciones de naturaleza predominantemente promocional, o cuyo objeto específico consista en divulgar, publicar o por cualquier forma dar a conocer instituciones, empresas, productos o servicios, según criterios de oportunidad comercial o industrial.

- Austria, Chipre, Eslovaquia, Eslovenia, Estonia, Finlandia, Hungría, Irlanda, Letonia, Lituania, Malta, Polonia, Reino Unido, República Checa y Suecia: No hay consensuada por las organizaciones profesionales ninguna definición al respecto. Periodista es todo aquel que ejerce dicha actividad en un medio de comunicación.

- FIP: Periodista es toda persona cuya actividad principal, regular y retribuida consiste en aportar su contribución para el texto, la palabra, o la imagen, a una o varias publicaciones de prensa escrita o audiovisual, esta actividad le reporta la parte principal de sus ingresos.

En el I Encuentro de Periodistas de la Comunidad Europea, celebrado a finales de 1989 en Pamplona, ya se vislumbraron algunos de los inconvenientes que podrían producirse -de cara a garantizar la libre circulación de periodistas- por las diferencias existentes entre las distintas definiciones y la alta ambigüedad que se desprenden de las mismas. Así como el desfase en el que se encuentran muchas de ellas que no han sido revisadas en los últimos años.

Valgan unas pocas situaciones hipotéticas para ilustrar estas dificultades. Por ejemplo, si un periodista que desee trabajar en Bélgica o en Luxemburgo, y en su Estado miembro de origen se haya caracterizado por desarrollar su labor profesional en la llamada prensa especializada tendrá problemas para que en estos países le sea reconocida su condición de periodista profesional; por cuanto sólo adquieren este status aquellos que trabajen en un medio de información general. Del mismo modo, un periodista alemán cuya actividad principal haya tenido lugar únicamente en Gabinetes o Direcciones y Consultoras de Comunicación (la denominada Comunicación Empresarial e Institucional), tendrá serios conflictos si pretende ejercer ahora labores de redactor en un medio de comunicación en Portugal (donde sólo los que disponen de la tarjeta que los acredita como periodistas profesionales pueden llevar a cabo esas funciones), puesto que la ocupación de relaciones públicas está expresamente excluida; al igual que en Francia, donde podrá ejercer pero no obtener el título de periodista profesional. Por su parte, en Italia, los problemas podrían surgir si no se ha desempeñado el Periodismo en exclusividad ni puede acreditarse suficientemente haber obtenido una cualificación equivalente a la exigida en este país latino. ¿Y qué podrá hacer un recién titulado en Periodismo en España sin la experiencia práctica ne- 
cesaria (de dos a cuatros años según los casos)? En los países que no establecen legalmente condiciones a posteriori no tendría ninguna limitación para ejercer en las mismas condiciones que los nacionales. En cambio, no podría trabajar como periodista ni en Italia ni en Portugal, ni tampoco le sería posible lograr el reconocimiento como periodista profesional en Francia, Bélgica y Luxemburgo (salvo que se esforzara por reunir los requisitos exigidos por estos países).

Conscientes de estas barreras y ante la postura de las Instituciones comunitarias de no adoptar ninguna medida para armonizar las condiciones de acceso a la profesión, los periodistas de la UE celebraron varios encuentros y debates -a lo largo de la década de los años noventa- con el fin de acercar posturas y unificar criterios. Todos los esfuerzos fueron vanos ${ }^{31}$. Sólo hubo unanimidad para presentar al Periodismo como una profesión abierta para todo aquel que, independientemente de su clase social o su formación, quiera ejercerla. Y para resaltar, al mismo tiempo, la necesidad de mejorar la formación tanto inicial como permanente del profesional de la información. Como mejor solución, para superar estas trabas que representan un obstáculo para la libre circulación, se apuntó el reconocimiento mutuo de acreditaciones. Es decir, que todo aquel que sea considerado periodista en un Estado miembro lo será asimismo en el resto.

¿Quiere decir esto, por ejemplo, que tanto Italia como Portugal, Francia, Bélgica y Luxemburgo exigirán a sus nacionales cumplir una serie de requisitos para acceder y ejercer como periodistas y no será así para un periodista español, sueco, inglés o alemán que desee trabajar en estos países? Ahora las discriminaciones afectarían a los periodistas nacionales para ejercer en sus propios países de origen, ya que estarían sujetos al cumplimiento forzoso de unas formalidades de las que, en cambio, quedarían exentos los informadores comunitarios.

Bien es cierto, como apuntan algunas organizaciones de periodistas, que el número de profesionales que se desplazan para ejercer el Periodismo en otro país de la UE distinto del suyo es más bien escaso ${ }^{32}$. Las principales dificultades no se derivan precisamente de los distintos sistemas de acceso. Como bien señaló el profesor Enrique de Aguinaga "un periodista puede y podrá decir me voy a trabajar a Dinamarca. Pero ya me contará usted que hace un periodista español allí. El odontólogo arranca las muelas igual en Amsterdam o Lisboa, pero el periodista no. El periodista debe, además de dominar perfectamente la lengua del país, estar inmerso en la sociedad en la que va a trabajar" (De la Cruz, 1989: 18) ${ }^{33}$. Sin embargo esto no es excusa para demorar por más tiempo el necesario acuerdo sobre quién es o quién no es periodista y en qué consiste realmente la actividad informativa conocida como Periodismo.

\footnotetext{
${ }^{31}$ Alfonso Díez se refiere al tema del acceso a la profesión periodística como "uno de los asuntos enquistados en el guión de cualquier reunión o debate internacional sobre la Información" (conferencia "Penetración del Sindicalismo en los medios", Córdoba 19 de enero de 1995).

${ }^{32}$ Esta realidad excluye como es lógico a los corresponsales y enviados especiales.

${ }^{33}$ Pero esta tendencia puede cambiar en los próximos años, a medida que se incremente entre los periodistas comunitarios un mejor y mayor conocimiento de las sociedades de los países miembros así como el dominio de sus lenguas.
} 
Es preciso recuperar la profesión periodística del claro estado de subdesarrollo en el que se encuentra. En palabras de la FAPE "una profesión periodística adecuadamente definida supone la garantía insustituible de idoneidad y competencia [...] debe ser entendida como la primera garantía que la Sociedad tiene acerca de las libertades civiles establecidas en el ámbito de la información y la libre expresión. [...] El principio de la libre contratación es y debe ser compatible con el principio de una profesión periodística definida" (FAPE, 1994: 11-13) ${ }^{34}$.

La definición debe comprender asimismo un estatuto profesional del periodista en el que se enumeren tanto los derechos que disfrutarán como los deberes que habrán de respetar. Del mismo modo conviene avanzar en la cuestión de la formación del periodista profesional. Así lo advirtió J.P. de Crayencour, en una reunión de periodistas comunitarios celebrada en Roma en 1968, cuando se estudiaban las materias que debían ser objeto de una coordinación para garantizar la libre circulación. A su juicio estas serían principalmente: el campo de actividad, las condiciones de formación, las reglas disciplinarias y la carta de periodista ${ }^{35}$. De similar parecer es el profesor de la Universidad Complutense Antonio Sánchez-Bravo, para el que las políticas comunitarias de información deben abarcar además: "libertad de expresión, pluralismo informativo, protección de los profesionales de los medios, códigos deontológicos y ética de la información, desconcentración de medios, protección del empleo, formación universitaria y continuada de los profesionales" (Sánchez-Bravo Cenjor, 1993: 58-59).

\section{Referencias bibliográficas, hemerográficas y webgráficas}

- Agrupación de Periodistas de UGT: www.agp-ugt.org

- Asociación de Periodistas Europeos: www.aje.org y www.apeuropeos.org

- Association Générale des Journalistes Professionnels de Belgique-AGPB/Algemene Vereniging van Beroepsjournalisten in België-AVBB (Bélgica): www.avbb.be

- Association Luxembourgeoise des Journalistes (Luxemburgo): www.alj.lu

- Comunidades Europeas (2003): Unión Europea, Tratados consolidados. Bélgica: Oficina de Publicaciones oficiales.

\footnotetext{
${ }^{34}$ Sin embargo, para esta organización profesional la definición de la profesión periodística como "garantía insustituible de idoneidad y competencia" no pasa por la exigencia obligatoria de la titulación académica específica y la consiguiente colegiación profesional, a pesar de lo señalado en su propuesta alternativa de Estatuto Profesional. No hay más que ver cuáles son los requisitos de acceso a cada una de las Asociaciones de la Prensa, que contemplan, en la mayoría de los casos, la ya mencionada triple vía.

${ }^{35}$ Crayencour, J.P.: "La profession de journaliste et le Traite de Rome", tema de su exposición en la reunión de periodistas de la CEE, Roma, 22 de marzo de 1968. Recogida como anexo en el documento de uso interno de la DG X: Le statut de la presse escrite dans les pays de la Communaute Europeenne, 1969.
} 
- Bohère, G. (1985): Profesión: periodista. Un estudio de los periodistas como trabajadores. Ginebra: Oficina Internacional del Trabajo.

- Boletín Oficial del Estado: www.boe.es

- Comisión Europea: europa.eu.int

- Consejo de la Unión Europea: ue.eu.int

- Dansk Journalistforbund (Dinamarca): www.journalistforbundet.dk

- Deutscher Journalistenverband-DJV (Alemania): www.djv.de

- Drustvo Novinarjev Slovenije (Eslovenia): www.novinar.com

- De Crayencour, J.P. (1982): Comunidad Europea y libre circulación de profesiones liberales. Convalidación de diplomas. Luxemburgo: Comisión de las Comunidades Europeas, Oficina de Publicaciones Oficiales.

- De La Cruz, M.A. (1989): “Aguinaga: La libre circulación de periodistas no afectará al periodismo porque no existe como profesión", en $Y A, 4$ de mayo, p. 18.

- Directiva 2005/36/CE del Parlamento y del Consejo, de 7 de septiembre de 2005, relativa al reconocimiento de cualificaciones profesionales (Texto pertinente a efectos del EEE). Diario Oficial n. ${ }^{\circ}$ L 255 de 30/09/2005, pp. 22-142.

- FAPE (1990): “XLIX Asamblea de la Federación de Asociaciones de la Prensa de España. I Encuentro con periodistas de la Comunidad Europea”, en Periodistas, 29, pp. 1-16, páginas centrales. (Sin firma)

- (1994): "Informe sobre la profesión periodística", en FAPE, 5, pp. 11-13. (Sin firma)

- (2005): "Estatuto del Periodista" en Periodistas [Fape], 2, pp. 41-44. (Sin firma)

- Federación Internacional de Periodistas: www.igj.oth

- Federación Panhelénica de Sindicatos de Periodistas (Grecia): www.poesy.gr

- Federation Nazionale della Stampa Italiana (Italia): www.fnsi.it

- Federation Suisse des Journalistes/Schweizer Verbandes des Journalistinnen und Journalisten (Suiza): www.journalisten.ch

- Gewerkschaft Druck, Journalismus, Papier (Austria): www.dup.or.at

- Gewerkschaft Kunst, Medien, Sport, Freire Berufe-KMSfB (Austria): www.kmsfb.at

- Journalists' Union of the Athens Daily Newspapers (Grecia): www.esiea.gr 
- Lirola Delgado, M.I. (1994): Libre circulación de personas y Unión Europea. Madrid: Fundación Universidad Empresa/Civitas.

- Magyar Ujságírók Országos Szövetsége-MUOSZ (Hungría): www.muosz.hu

- Malta Press Club: www.maltapressclub.org.mt

- Nederlandse Vereniging van Journalisten-NVJ (Países Bajos): www.villamedia.nl y www.nvj.nl

- Norsk Journalistforbund, Asociación de la Prensa (Noruega): www.nj.no/njf

- Norsk Journalistlag, Sindicato de Periodistas (Noruega): www.nj.no

- Ordine dei Giornalisti (Italia): www.odg.it

- Organización Internacional de Trabajadores (1990): Reunión tripartita sobre las condiciones de empleos y de trabajo de los periodistas. Ginebra: Oficina Internacional del Trabajo.

- Österreichischen Gewerkschaftsbund-ÖGB (Austria): www.oegb.or.at

- Parlamento Europeo: www.europarl.eu.int y www.europarl.es

- Proposición de Ley del "Estatuto del Periodista Profesional” en www.xornalistas.com/pdf/PLEPP.pdf

- Real Rodríguez, E. (2003): Formación y ejercicio profesional del periodista en la España del siglo XXI dentro del marco de la Unión Europea (2 vol.). Tesis doctoral. Madrid: Universidad Complutense.

- Sánchez-Bravo Cenjor, A. (1993): La información en la Comunidad Europea. Madrid: Editorial Síntesis.

- Sindicat dés Medios/Die Mediengewerkschaft-Comedia (Suiza): www.comedia.ch

- Sindicato de Periodistas de la Prensa Diaria de Atenas: www.esiea.gr

- Sindicato de Periodistas Lituanos: www.aiva.lt/LJU

- Sindicato dos Jornalistas (Portugal): www.jornalistas.online.pt

- Sindikat Novinarjev Slovenije (Eslovenia): www.novinar.com/sindilkat

- Slovensky Syndikat Novinarov (Eslovaquia): www.ssn.sk

- Societé des Auteurs Journalistes-SAJ (Bélgica): www.saj.be

- Stowarzyszenie Dziennikarzy Polskich-SDP (Polonia): www.sdp.pl

- Stowarzyszenie Dziennikarzy Rzeczypospolitej Polskiej-SDRP (Polonia): www.stow-dznien.org.pl

- Suomen Journalistiliitto-Finlands Journalistförbund (Finlandia): www.journalistiliitto.fi 
- Svenska Journalistförbundet (Suecia): www.sjf.se

- Syndicat National des Jorunalistes (Francia): www.snf.fr

- Syndikat Novináru Ceské Republiky (República Checa): www.syndikat-novinaru.cz

- Union of Cyprus Journalists (Chipre): www.logos.cy.net/bussiness/non-profit/ucj

- Union Syndicale des Journalistes-CFDT (Francia): www.usj-cfdt.fr

- Vereinten Dienstleistungsgewrkschaft (Alemania): www.verdi.de

- VV.AA. (1990): La organización de los periodistas en 1993. Madrid: Asociación de la Prensa.

- VV.AA. (2000): Professione giornalista. Bolonia: Il Mulino. 